\title{
The Severity of Infection Determines the Localization of Damage and Extent of Sensorineural Hearing Loss in Experimental Pneumococcal Meningitis
}

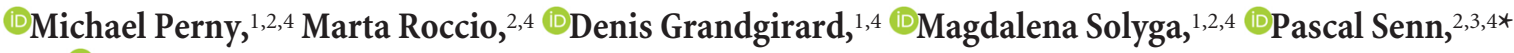 \\ and $\left(\mathbb{S}^{-S t e p h e n ~ L . ~ L e i b ~}{ }^{1,4 *}\right.$ \\ ${ }^{1}$ Neuroinfection Laboratory, Institute for Infectious Diseases, University of Bern, 3001 Bern, Switzerland, ${ }^{2}$ Laboratory of Inner Ear Research, Department of \\ Clinical Research, University of Bern and University Department of Otorhinolaryngology, Head \& Neck Surgery, Inselspital, 3008 Bern, Switzerland, \\ ${ }^{3}$ Department of Otorhinolaryngology, Head and Neck Surgery, University Hospital Geneva, 1205 Geneva, Switzerland, and ${ }^{4}$ Cluster for Regenerative \\ Neuroscience, Department of Clinical Research, University of Bern, 3008 Bern, Switzerland
}

Hearing loss is an important sequela of pneumococcal meningitis (PM), occurring in up to $30 \%$ of survivors. The role of the severity of infection on hearing function and pathomorphological consequences in the cochlea secondary to PM have not been investigated to date. Using a well-established model of PM, we systematically investigated the functional hearing outcome and the long-term fate of neurosensory cells in the cochlea, i.e., hair cells and spiral ganglion neurons (SGNs), with a focus on their tonotopic distribution. Intracisternal infection of infant rats with increasing inocula of Streptococcus pneumoniae resulted in a dose-dependent increase in CSF levels of interleukin-1 $\beta$, interleukin-6, tumor necrosis factor $\alpha$, interleukin-10, and interferon- $\gamma$ in acute disease. The severity of long-term hearing loss at 3 weeks after infection, measured by auditory brainstem response recordings, correlated to the initial inoculum dose and to the levels of proinflammatory cytokines determined in the acute phase of PM. Quantitative cochlear histomorphology revealed a significant loss of SGNs and outer hair cells that strongly correlated to the level of infection, with the most severe damage occurring in the basal part of the cochlea. Inner hair cells (IHCs) were not significantly affected throughout the entire cochlea. However, surviving IHCs lost synaptic connectivity to remaining SGNs in all cochlear regions. These findings provide evidence that the inoculum concentration, i.e., severity of infection, is the major determinant of long-term morphological cell pathologies in the cochlea and functional hearing loss.

Key words: animal model; hair cells; pneumococcal meningitis; sensorineural hearing loss; spiral ganglion neurons; streptococcus pneumonia

Significance Statement

Hearing loss is a neurofunctional deficit occurring in up to $30 \%$ of patients surviving pneumococcal meningitis (PM). Here, we analyze the correlation between the severity of infection and the inflammatory response in the CSF, the tonotopic distribution of neurosensory pathologies in the cochlea, and the long-term hearing function in a rat model of pneumococcal meningitis. Our study identifies the severity of infection as the key determinant of long-term hearing loss, underlining the importance of the prompt institution of antibiotic therapy in patients suffering from PM. Furthermore, our findings reveal in detail the spatial loss of cochlear neurosensory cells, providing new insights into the pathogenesis of meningitis-associated hearing loss that reveal new starting points for the development of otoprotective therapies.

\section{Introduction}

Pneumococcal meningitis (PM) is associated with a high risk of neurological sequelae, of which sensorineural hearing loss
(SNHL) is the most common long-term deficit, occurring in up to $30 \%$ of surviving patients (van de Beek et al., 2004; Edmond et al., 2010; Chandran et al., 2011). The infection, as well as the
Received Feb. 19, 2016; revised June 6, 2016; accepted June 9, 2016.

Author contributions: M.P., M.R., D.G., P.S., and S.L.L. designed research; M.P. and M.S. performed research; M.P., M.R., D.G., P.S., and S.L.L. analyzed data; M.P., M.R., D.G., P.S., and S.L.L. wrote the paper.

This work was supported by the European Commission (0TOSTEM Grant FP7-Health-603029, to P.S., S.L.L.) and the Swiss National Science Foundation (Grant 310030_162583 to S.L.L.). Images were acquired using equipment supported by the Microscopy Imaging Center of the University of Bern. We thank Fabian Liechti for guidance in the experimental setup and Franziska Simon and Belinda Ries for excellent technical assistance.
*P.S. and S.L.L. contributed equally to this work.

The authors declare no competing financial interests.

Correspondence should be addressed to Dr. Stephen L. Leib, Neuroinfection Laboratory, Institute for Infectious Diseases, University of Bern, Friedbühlstrasse 51, 3001 Bern, Switzerland. E-mail: stephen.leib@ifik.unibe.ch. DOI:10.1523/JNEUROSCI.0554-16.2016

Copyright $\odot 2016$ the authors $\quad 0270-6474 / 16 / 367740-10 \$ 15.00 / 0$ 
inflammatory response, damages the mechanosensitive hair cells, located in the organ of Corti (OC) and the spiral ganglion neurons (SGNs), critical neurosensory cells responsible for the peripheral hearing process (Wong and Ryan, 2015).

During the development of meningitis-associated SNHL, pneumococci and leukocytes from the CSF primarily infiltrate the perilymphatic space via the cochlear aqueduct (van de Beek et al., 2004; Edmond et al., 2010; Chandran et al., 2011; Møller et al., 2014), leading to an accentuated inflammation in the basal turn of the cochlea (Klein et al., 2003; Brandt et al., 2006; Wong and Ryan, 2015). A variety of proinflammatory cytokines and chemokines such as interleukin- $1 \beta$ (IL-1 $\beta)$, IL-6, IL-8, tumor necrosis factor $\alpha$ (TNF- $\alpha$ ), and interferon- $\gamma($ IFN- $\gamma$ ) are released in the acute phase of PM (Täuber and Moser, 1999; Coutinho et al., 2013). Alleviating this overshooting inflammatory response and its byproducts with antioxidants or anti-inflammatory drugs has been partially successful to reduce hearing loss (Kastenbauer et al., 2001; Ge et al., 2004; Aminpour et al., 2005; Meli et al., 2006; Coimbra et al., 2007; Grandgirard et al., 2007, 2012; Liechti et al., 2014a, 2015a). Among these cytokines, TNF- $\alpha$ alone is able to induce a predominant loss of outer hair cells (OHCs), mainly in the basal turn area of OC explants ex vivo (Haake et al., 2009; Wu et al., 2015).

In addition to the inflammatory response, the exotoxin pneumolysin released by Streptococcus pneumoniae is known to be strongly ototoxic (Winter et al., 1997; Beurg et al., 2005).

Functional hearing assessment revealed increased hearing thresholds upon experimental pneumococcal meningitis already during the acute phase of the disease that persisted until later stages. The degree of hearing threshold shifts in the acute phase was shown to be dependent on the bacterial inoculum (INO); however, the effect on long-term hearing loss as a function of bacterial load has not been investigated to date (Klein et al., 2003; Coimbra et al., 2007; Demel et al., 2011; Grandgirard et al., 2012).

Despite the critical role hair cells play in the process of hearing, only a few studies have analyzed the status of the OC after experimental pneumococcal meningitis. These have shown morphological damage to hair cells and their stereocilia; however, they were performed in only a qualitative or semiquantitative manner (Winter et al., 1996; Rappaport et al., 1999; Brandt et al., 2006). Previous studies have focused mainly on the fate of SGNs, revealing a decreased density in the basal ganglia 2 weeks after infection (Klein et al., 2003; Brandt et al., 2006; Meli et al., 2006; Demel et al., 2011).

Here we provide for the first time an anatomical analysis of the fate of neurosensory cells after pneumococcal meningitis (Leib et al., 2000; Liechti et al., 2014a) to better understand the pathogenesis of SNHL. We analyzed the effect of the severity of infection on the immune response, hearing function, and the survival of the cochlear neurosensory cells, i.e., hair cells and spiral ganglion neurons. Our work identifies the initial bacterial inoculum and the severity of subsequent infection as key regulators determining the degree of inflammatory response and the following long-term intracochlear cell pathologies. We show the spatial loss of spiral ganglion neurons and hair cells, occurring with a basal to apical gradient. Additionally, we show for the first time quantitatively that predominantly outer hair cells are affected and that surviving inner hair cells (IHCs) lost synaptic connectivity to remaining spiral ganglion neurons.

Our work underlines the beneficial role of prompt institution of antibiotic therapy in a clinical setting to reduce bacterial pro- liferation and thereby preventing long-term meningitis-induced SNHL.

\section{Materials and Methods}

\section{S. pneumoniae inoculum}

A clinical isolate of Streptococcus pneumoniae (serotype 3) from a patient with bacterial meningitis was used for the experiments as reported previously (Leib et al., 2000). Briefly, the bacteria were cultured overnight in brain-heart infusion medium, subsequently diluted 1:10 in fresh medium and grown for $5 \mathrm{~h}$ to logarithmic phase, and eventually centrifuged for $10 \mathrm{~min}$ at $3100 \mathrm{rpm}$ at $4^{\circ} \mathrm{C}$. The pellet was resuspended in sterile, pyrogen-free saline to the desired optical density and used for intracisternal infections as described below. The accuracy of the inoculum concentration was always confirmed by quantitative cultures on Columbia sheep blood agar (CSBA) plates.

\section{Infant rat model of pneumococcal meningitis}

All animal studies were approved by the Animal Care and Experimentation Committee of the Canton of Bern, Switzerland (licenses BE 100/11 and BE 129/14) and followed the Swiss national guidelines for the performance of animal experiments. A well-described infant rat animal model of PM was used for the experiments, as described previously (Grandgirard et al., 2012). Wistar rat pups (males) were ordered from Charles River Laboratories and acclimatized for $6 \mathrm{~d}$. Intracisternal infection was performed on postnatal day 11 with $10 \mu \mathrm{l}$ of $\mathrm{NaCl}$ containing $1.7 \times 10^{2} \pm 58$ colony-forming units (cfu) (low inoculum), $8.3 \times 10^{2} \pm$ $1.7 \times 10^{2} \mathrm{cfu}$ (intermediate inoculum), or $1.1 \times 10^{4} \pm 1.8 \times 10^{3} \mathrm{cfu}$ (high inoculum) live S. pneumoniae. The inoculum dosages were within the range of those published previously (Klein et al., 2003; Grandgirard et al., 2012; Liechti et al., 2014b). Control animals were injected intracisternally with $10 \mu \mathrm{l}$ of $\mathrm{NaCl}$. Pneumococcal meningitis was confirmed $18 \mathrm{~h}$ after infection with quantitative cultures of the CSF, when the animals in the intermediate and high inoculum groups typically became symptomatic. For this, $5 \mu$ l of CSF was collected by puncture of the cisterna magna, followed by overnight cultivation on a CSBA plate. At the same time, antibiotic therapy was initiated with ceftriaxone (Rocephine, Roche Pharma) at a dose of $2 \times 100 \mathrm{mg} \cdot \mathrm{kg}^{-1} \cdot \mathrm{d}^{-1}$, intraperitoneally, and continued for $2 \mathrm{~d}$.

\section{Cytokine analysis in CSF}

A panel of PM-associated cytokines-IL-1 $\beta$, IL-6, TNF- $\alpha$, IL-10, and IFN- $\gamma$ - was assessed using a microsphere-based multiplex assay (MILLIPLEX MAP Kit, Rat Cytokine/Chemokine Magnetic Bead Panel, catalog \#RECYTMAG-65K; Millipore Corporation) and a Bio-Plex 200 station (Bio-Rad Laboratories). Five microliters of CSF harvested and centrifuged $18 \mathrm{~h}$ after infection were diluted to a final volume of $25 \mu \mathrm{l}$ using the provided assay buffer. At least 50 beads were measured for each analyte. Calibration curves from recombinant standards were calculated with Bio-Plex Manager software, version 4.1.1, using a five-parameter logistic curve fitting. For samples below the detection limit, the value of detection limit provided by the manufacturer (TNF- $\alpha, 9.5 \mathrm{pg} / \mathrm{ml}$; IL-6, $153.5 \mathrm{pg} / \mathrm{ml}$; IL-1 $\beta, 14 \mathrm{pg} / \mathrm{ml}$; IL-10, $13.5 \mathrm{pg} / \mathrm{ml}$ IFN- $\gamma, 31 \mathrm{pg} / \mathrm{ml}$ ) was multiplied by the dilution factor.

\section{Click-and pure tone-evoked auditory brainstem response}

Auditory brainstem responses (ABRs) were recorded in response to click stimulations (presentation rate, 20 clicks/s) on both ears. Animals were anesthetized by intraperitoneal injection of a mixture of ketamine (75 $\mathrm{mg} / \mathrm{kg}$ ) and xylazine $(5 \mathrm{mg} / \mathrm{kg})$. Subdermal needle electrodes were placed on the mastoid of the tested ear (active), at the vertex (reference), and in the leg muscles (ground). The sound stimulus consisted of $100 \mu \mathrm{s}$ square-wave impulses synthesized digitally using SigGen software (Tucker-Davis Technologies, System II) fed into a programmable attenuator and, after digital-to-analog conversion, transduced by a speaker (JBL model $2405 \mathrm{H}$ ) located $4 \mathrm{~cm}$ away from the pinna. ABR recordings were amplified, bandpass filtered between $100 \mathrm{~Hz}$ and $3 \mathrm{kHz}$ (Ithaco model 1201), and averaged ( $n=500)$ during a $12 \mathrm{~ms}$ window using the data acquisition software BioSig (Tucker-Davis Technologies System II). The intensity of the click stimulus was reduced from 110 to $0 \mathrm{~dB}$ sound 
pressure level (SPL) in $5 \mathrm{~dB}$ steps. The hearing threshold was defined as the lowest intensity that induced the appearance of a visually detectable first peak, and the average from both ears was calculated.

Pure tone ABR recordings were performed with the Intelligent Hearing Systems SmartEP system. Five millisecond pure tone pips (Blackman envelope; polarity alternating) were presented at a rate of $21.1 \mathrm{~s}^{-1}$, ranging from 100 to $20 \mathrm{~dB}$ SPL in $10 \mathrm{~dB}$ decrements $(5 \mathrm{~dB}$ decrements close to threshold). Responses were measured at 4, 8, 16, and $32 \mathrm{kHz}$. A total of 1024 responses were averaged at each sound level and filtered between 100 and $1500 \mathrm{~Hz}$. Again, the hearing threshold was defined as the lowest intensity that induced the appearance of a visually detectable first peak.

\section{Immunohistological assessment of spiral ganglion neuron density} Three weeks after infection, the animals were perfused with $4 \%$ paraformaldehyde (PFA). Cochleas were dissected and isolated followed by overnight fixation in $4 \% \mathrm{PFA}$ at $4^{\circ} \mathrm{C}$. The right cochleas were used for spiral ganglion histology, whereas the left cochleas were used for hair cell analysis (see the following section). Samples were decalcified with Osteosoft (Merck) for $6 \mathrm{~d}$ before ethanol dehydration followed by paraffin embedding. Ten micrometer midmodiolar sections were cut and mounted on Superfrost Plus microscopy slides (Thermo Fisher Scientific). Xylene was used for deparaffinization. The entire immunofluorescence procedure was performed with a Shandon Sequenza staining rack (Thermo Fisher Scientific). Sections were permeabilized for $5 \mathrm{~min}$ with $0.1 \%$ Triton X-100 and then blocked with a blocking solution (2\% BSA plus $0.01 \%$ Triton $\mathrm{X}-100$ in PBS) for $1 \mathrm{~h}$ at room temperature. The neuron-specific primary antibody against $\beta$-III Tubulin (TUJ) (monoclonal mouse anti $\beta$-III Tubulin, R\&D Systems) was diluted 1:500 in blocking solution and incubated overnight at $4^{\circ} \mathrm{C}$. The slides were rinsed three times with PBS and incubated with the secondary antibody (Alexa Fluor conjugated, Invitrogen) diluted 1:500 in blocking solution for $2 \mathrm{~h}$ at room temperature. After rinsing again three times with PBS, the samples were mounted with a coverslip using Fluoroshield containing DAPI (Sigma). Images of the spiral ganglion were acquired with a Zeiss 710 laser scanning microscope using Zeiss Plan-Apochromat $10 \times 0.3 \mathrm{nu}-$ merical aperture (NA) and Plan-Apochromat $20 \times 0.8$ NA objectives.

\section{Organ of Corti whole-mount immunofluorescence}

The fixed and decalcified left cochleas were fine dissected with forceps (World Precision Instruments) and sapphire blades (World Precision Instruments) using a Nikon SMZ800 binocular microscope. The bony shell was removed to expose the OC, followed by removal of the stria vascularis and separation from the spiral ganglion. Each turn of the spiral shaped OC was cut to make flat mounting on a glass slide possible. The basal and middle turns were cut in two pieces each, and the apical turn was left as one piece, resulting in five pieces per OC. The tissue pieces were then permeabilized with $3 \%$ Triton X-100 for $30 \mathrm{~min}$, rinsed three times with PBS, and incubated in blocking solution for $1 \mathrm{~h}$ at room temperature. The hair cell-specific antibody against Myosin7a (polyclonal rabbit anti Myosin-7a, Proteus) together with the presynaptic ribbon-specific antibody against CtBP2 (monoclonal mouse anti CtBP2, BD Bioscience) were both diluted 1:200 in blocking solution and incubated overnight at $4^{\circ} \mathrm{C}$. The tissues were rinsed three times with PBS and incubated with the secondary antibodies (Alexa Fluor conjugated, Invitrogen) diluted 1:500 in blocking solution for $2 \mathrm{~h}$ at room temperature. Each tissue piece was rinsed with PBS and mounted on Superfrost Plus microscopy slides (Thermo Fisher Scientific) using Fluoroshield containing DAPI (Sigma). Image acquisition was performed with a Zeiss 710 laser scanning microscope using a Zeiss Plan-Apochromat $10 \times 0.3 \mathrm{NA}$ (optical zoom, 2) objective for hair cell quantification and a PlanApochromat $60 \times 1.4$ NA (optical zoom, 2-3) objective for presynaptic ribbon quantification.

\section{Data analysis}

Spiral ganglion neuron density. The density of spiral ganglion neurons was calculated by counting colabeled TUJ-positive and DAPI-positive cells located in the Rosenthal's canal of the basal, middle, and apical turns. Five nonconsecutive midmodiolar sections were chosen from a total of about 25 sections for quantification (see Fig. $3 A$ ). The number of spiral ganglion neurons was then divided by the area of the corresponding
Rosenthal's canal, calculated using the open source image processing software FIJI, version 2.0. The measured densities were averaged to calculate the overall density for each cochlear region.

Hair cell quantification. Hair cell quantification was performed by counting colabeled Myosin7a-positive and DAPI-positive cells in OC whole-mount preparations. Five random microscopic fields, encompassing a total of 150-175 IHCs and 600-700 OHCs, were analyzed for each cochlear region (basal, middle, and apical turns). The number of hair cells (IHCs and OHCs) was divided by the length of the basilar membrane analyzed and expressed per unit length of $100 \mu \mathrm{m}$.

Presynaptic ribbon quantification. Presynaptic ribbons were quantified by counting labeled CtBP2 punctae of IHCs in the basal, middle, and apical turns of $\mathrm{OC}$ whole-mount preparations. For each cochlear region, five random microscopic fields were analyzed, each displaying 7-8 IHCs (in total 105-120 IHCs per cochlea). The total number of CtBP2 punctae was divided by the total number of IHCs for each image to obtain an averaged number of ribbons per IHC for each cochlear region.

\section{Statistical analysis}

Graph Pad Prism software, version 6.0, was used for statistical analyses. Unpaired Student's $t$ tests with Welch's correction or one-sample $t$ tests were used for single comparisons. Correlation analysis was performed with the Spearman method. The specific statistical analysis is described in each figure legend. A $p$ value of $<0.05$ (two tailed) was considered as statistically significant.

\section{Results}

\section{Dose-dependent bacterial growth and inflammatory response} in the CSF

We set out to assess the effect of the severity of the infection, i.e., the bacterial concentration of the initial inoculum, on bacterial growth and the resulting cytokine levels in the CSF during the acute phase of experimental pneumococcal meningitis, using a previously established model (Grandgirard et al., 2012). Infecting the animals with three different doses of live S. pneumoniae (low INO, $1.7 \times 10^{2} \pm 58 \mathrm{cfu}$; intermediate INO, $8.3 \times 10^{2} \pm 1.7 \times$ $10^{2} \mathrm{cfu}$; high INO, $\left.1.1 \times 10^{4} \pm 1.8 \times 10^{3} \mathrm{cfu}\right)$ resulted in a dose-dependent bacterial concentration in the CSF, measured $18 \mathrm{~h}$ after infection (Fig. 1A). Infecting the animals with the low INO did not result in a statistically significant increased bacterial CSF concentration after $18 \mathrm{~h}$. However, we found a strong positive correlation between the bacterial inoculum load and the CSF bacterial concentration in the acute phase at $18 \mathrm{~h}$ after infection (Spearman's $r=0.86, p<0.0001, n=24$ ) before initiation of the antibiotic therapy.

Proinflammatory and anti-inflammatory cytokines were measured in the CSF at $18 \mathrm{~h}$ after infection (Fig. $1 B-F)$. Levels of IL-1 $\beta(p<0.001)$, IL-6 ( $p<0.001)$, TNF- $\alpha(p<0.01)$, IL-10 $(p<0.001)$, and IFN- $\gamma(p<0.05)$ were significantly higher after infection with high INO compared to controls. Levels of IL-1 $\beta$ $(p<0.05)$, IL-6 ( $p<0.05)$, and TNF- $\alpha(p<0.05)$ were also increased after infection with the intermediate INO, whereas only the levels of IL-1 $\beta(p<0.05)$ were increased after low INO infection. The level of IL- 6 did not reach statistical significance $(p=0.056)$ upon infection with the low INO.

We observed a strong positive correlation between the CSF bacterial concentration and the levels of IL-1 $\beta$ (Spearman's $r=$ $0.86, p<0.0001, n=31$ ), IL-6 (Spearman's $r=0.90, p<0.0001$, $n=31$ ), and TNF- $\alpha$ (Spearman's $r=0.87, p<0.0001 n=31)$ in the acute phase at $18 \mathrm{~h}$ after infection.

\section{Decreased hearing thresholds 3 weeks after infection}

To evaluate the long-term consequences of the severity of the bacterial infection and the subsequent inflammatory host re- 
A
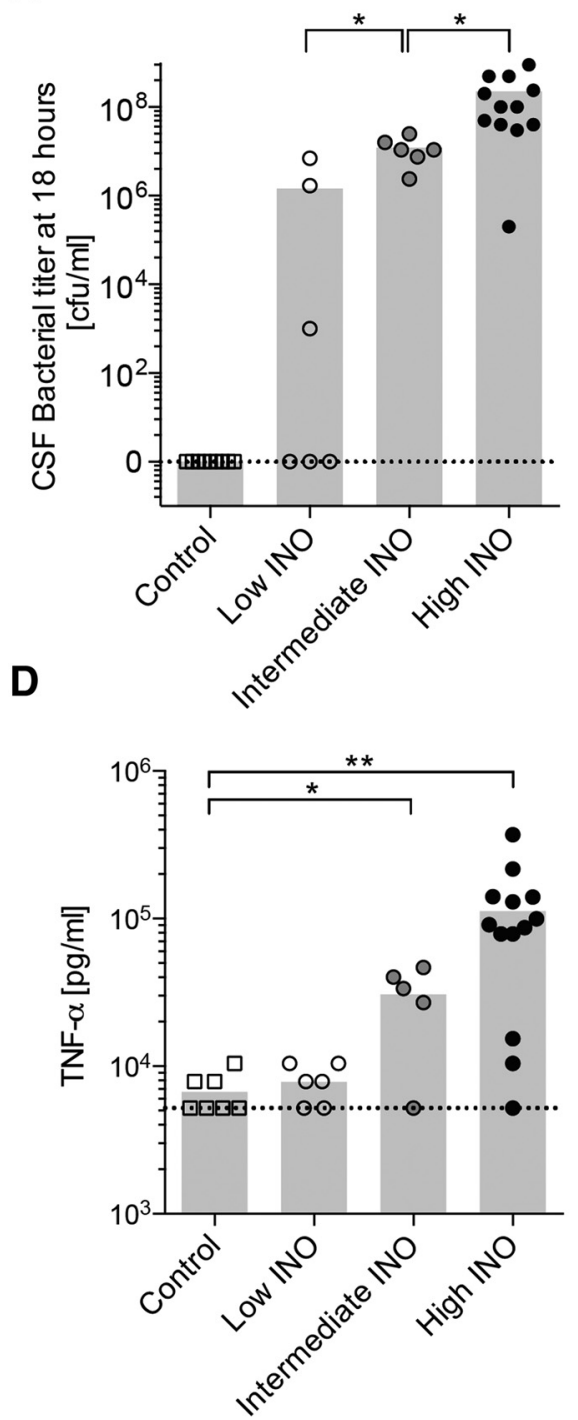

B
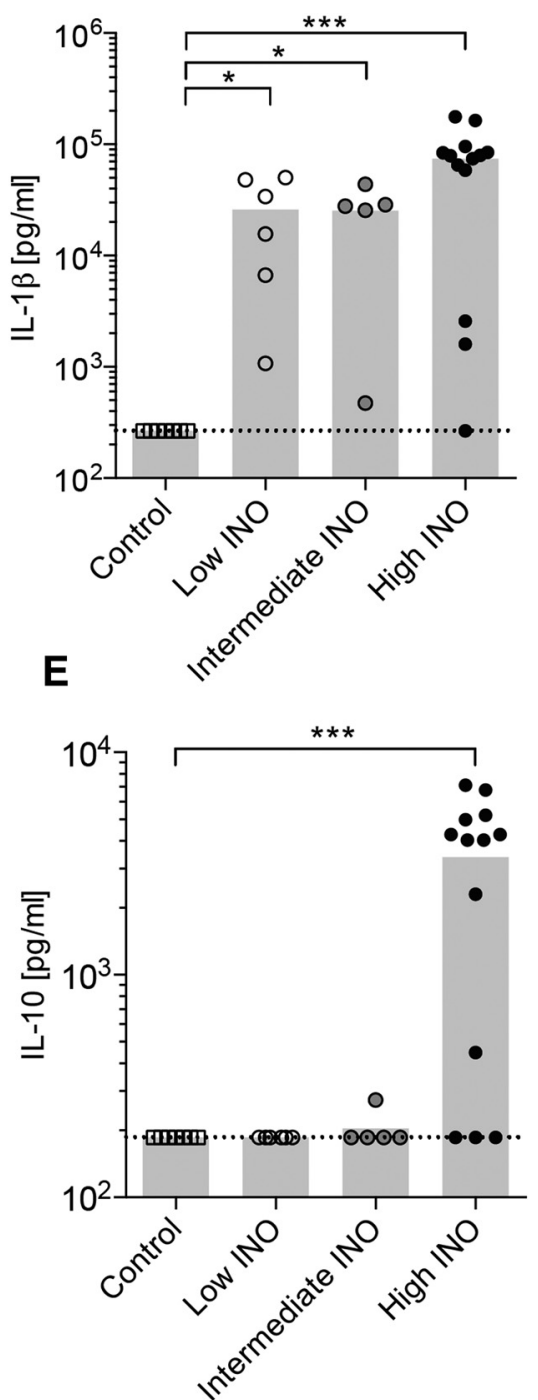

C
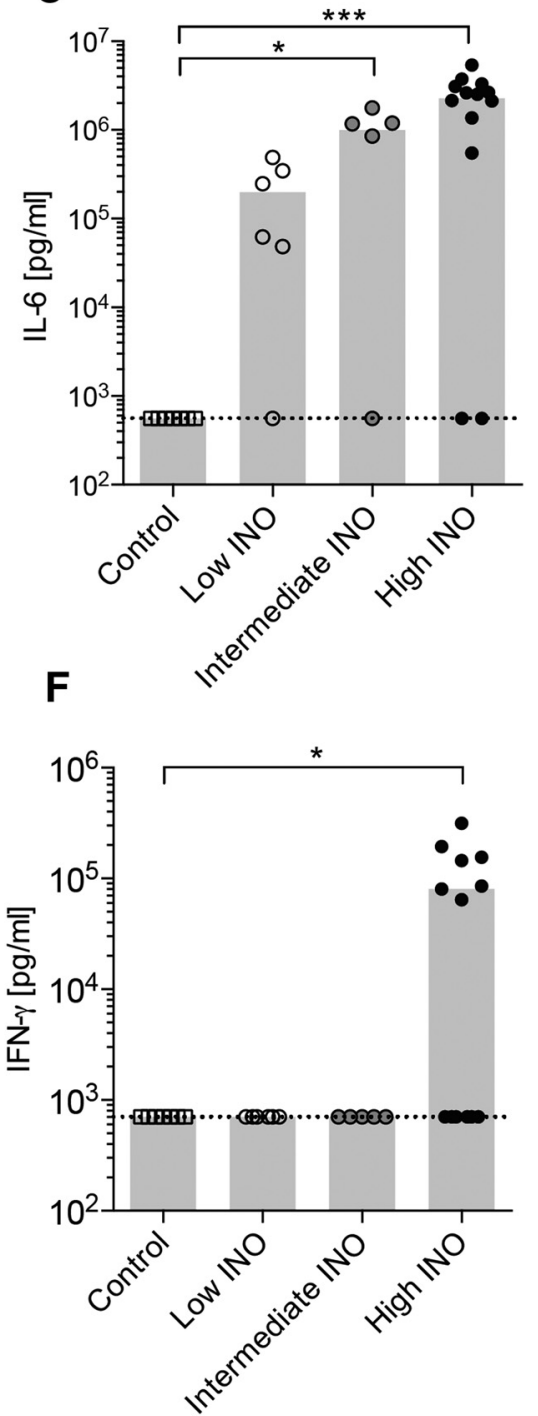

Figure 1. Dose-dependent bacterial growth and cytokine profile in the CSF $18 \mathrm{~h}$ after infection with S. pneumoniae. A, Dose-dependent growth of S. pneumoniae in the CSF determined at $18 \mathrm{~h}$ after infection. $\boldsymbol{B}-\boldsymbol{F}$, The levels of IL-1 $\beta(\boldsymbol{B})$, IL-6 (C), TNF- $\alpha(\boldsymbol{D})$, IL-10 (E), and IFN- $\gamma(\boldsymbol{F})$ were measured in the CSF $18 \mathrm{~h}$ after infecting the animals intracisternally with three different loads of $S$. pneumoniae ( $n=5-13$ animals per group). The means are indicated in the bar graphs. The dashed lines indicate the detection limit for each cytokine. An unpaired $t$ test with Welch's correction was used for single comparisons. ${ }^{*} p<0.05 ;{ }^{* *} p<0.01 ;{ }^{* * *} p<0.001$.

sponse on the hearing function, we performed auditory evoked brainstem response recordings 3 weeks after infection. Rats were tested with a broadband click stimulus and pure tones to determine hearing thresholds. Representative click-ABR recordings from a control and an infected (high INO) rat are shown in Figure $2, A$ and $B$, respectively. No detectable waves were generated below $35 \mathrm{~dB}$ for the control rat and $80 \mathrm{~dB}$ for the infected rat (Fig. 2A,B).

Comparing ABR recordings of rats inoculated with the three different doses of S. pneumoniae revealed a dose-dependent increase of hearing thresholds (Fig. 2C). We did not observe a significant shift in hearing threshold with the low INO $(36.7 \pm 3.8$ $\mathrm{dB})$, whereas the hearing thresholds with the intermediate INO $(49.17 \pm 8.9 \mathrm{~dB}, p<0.05)$ and high INO $(95.8 \pm 9.0 \mathrm{~dB}, p<$ $0.0001)$ were significantly higher compared to control animals $(35.6 \pm 3.7 \mathrm{~dB})$.

Pure tone ABR testing of a subset of animals infected with the intermediate INO revealed a frequency-dependent threshold shift (Fig. 2D). We observed a significant threshold shift compared to controls at 32,16 , and $8 \mathrm{kHz}$. There was no significant shift with the lowest frequency at $4 \mathrm{kHz}$. Normalizing the data to the hearing threshold at $4 \mathrm{kHz}$ for each animal showed that the threshold shift significantly increases (18.3 $2.90 \mathrm{~dB}$ at $32 \mathrm{kHz}, p<0.01$; Fig. $2 E$ ) toward the high frequencies. Control animals showed instead an opposite gradient of hearing sensitivity, with decreasing hearing thresholds toward the high frequencies $(-4.7 \pm 0.6 \mathrm{~dB}$ at $16 \mathrm{kHz}, p<0.01$; $-13.3 \pm 2.9 \mathrm{~dB}$ at $32 \mathrm{kHz}, p<0.05)$. This indicates a predominant damage in the basal turn of the cochlea in infected animals. No frequency dependency was observed in animals with severe hearing loss ( $>90 \mathrm{~dB}$ hearing threshold; data not shown).

In agreement with the observed ototoxic effect reported for TNF- $\alpha$ (Haake et al., 2009; Wu et al., 2015), the hearing thresholds (click-ABR) 3 weeks after infection correlated with the CSF levels of TNF- $\alpha$ in the acute phase of the disease (Fig. 2F; Spearman's $r=0.86, p<0.0001)$. Additionally, acute phase levels of IL- $1 \beta$ (Spearman's $r=0.58, p<0.05$ ) and IL-6 


\section{A}

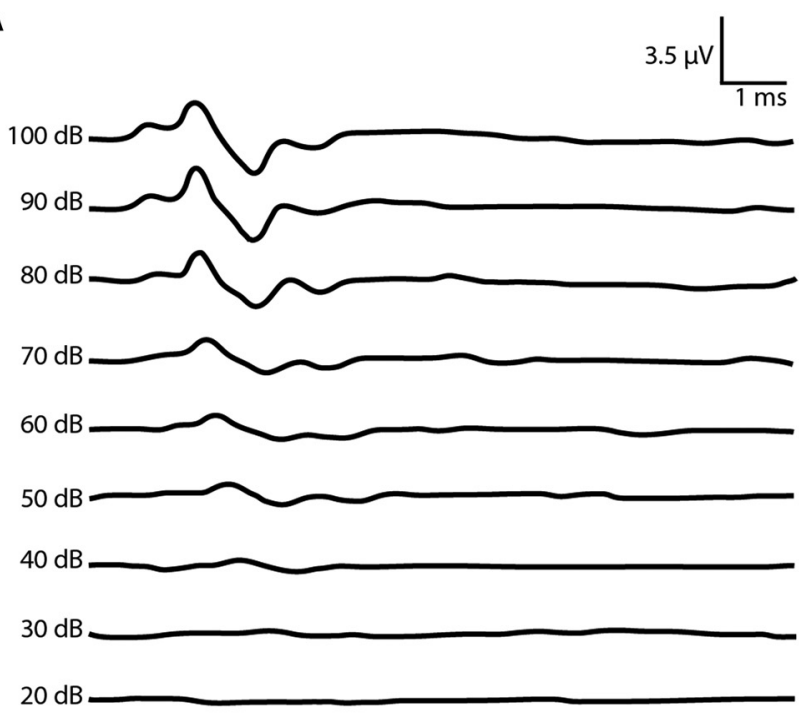

B

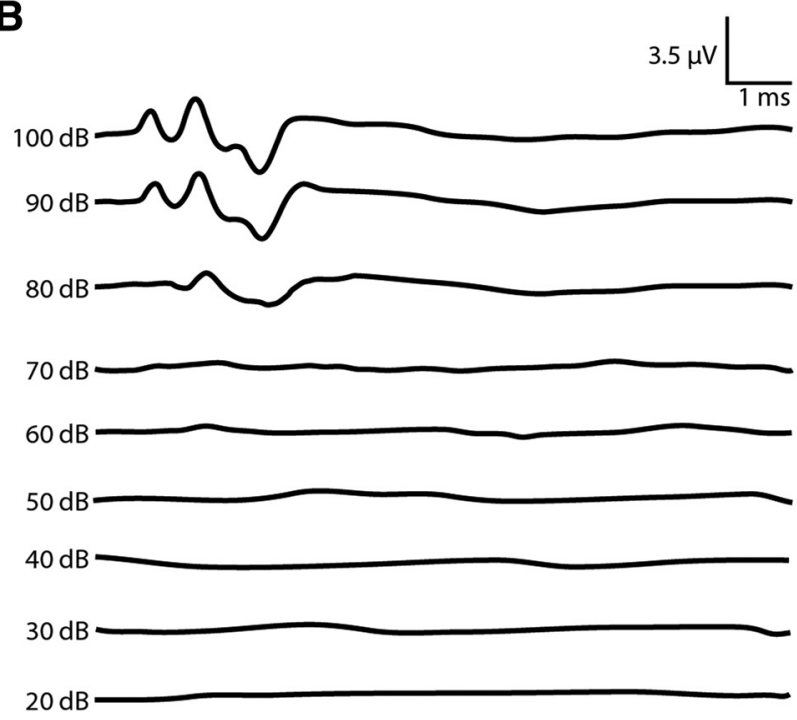

C

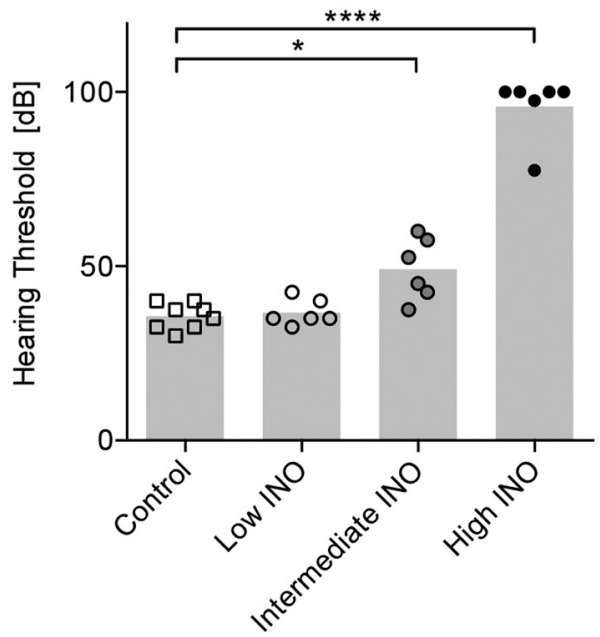

E

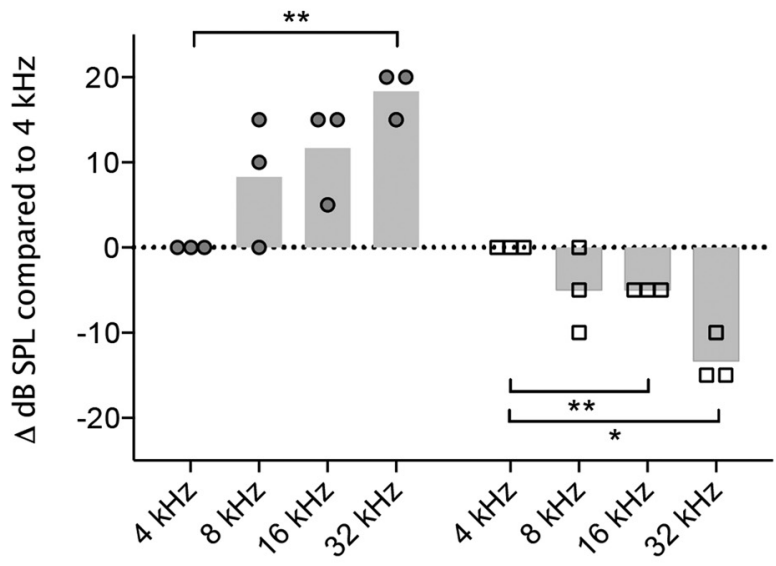

D

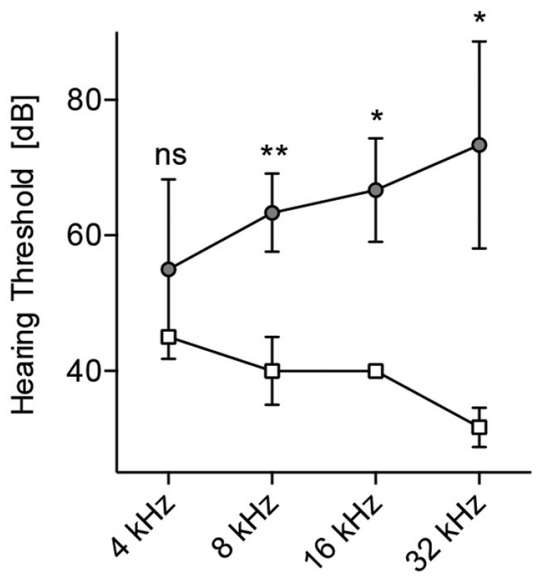

F

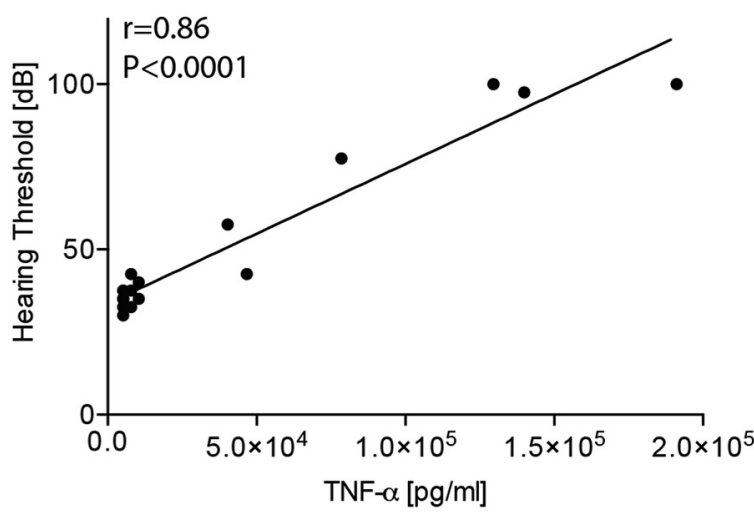

Intermediate INO

Control

Figure 2. Increased hearing thresholds 3 weeks after infection with S. pneumoniae. $A, B$, The representative figures show the hearing threshold of a control animal $(A)$ of $\sim 40 \mathrm{~d} B$ and an infected animal $(\boldsymbol{B})$ with a hearing threshold around $80 \mathrm{~dB}$. C, Increasing inoculum concentrations elevated hearing thresholds in a dose-dependent way. ABR recordings were performed in $n=6-8$ animals per group. The means are indicated by the bar graph. An unpaired $t$ test with Welch's correction was used for single comparisons. $D$, Frequency-dependent hearing thresholds (controls, empty squares; intermediate INO, gray circles; $n=3$ animals per group). The mean $\pm S D$ is shown. An unpaired $t$ test with Welch's correction was used for single comparisons. $E$, Frequency-dependent threshold shifts. Data are normalized for each animal individually (threshold at $4 \mathrm{kHz}$ set to 0 ). A one-sample $t$ test was used for single comparisons. $\boldsymbol{F}$, Spearman's correlation between TNF- $\alpha$ levels in the CSF during the acute phase and the hearing thresholds in the late phase of disease (3 weeks after infection). ${ }^{*} p<0.05 ;{ }^{* *} p<0.01 ;{ }^{* * *} p<0.0001$. 
(Spearman's $r=0.71, p<0.001$ ) correlated with the late phase hearing thresholds.

\section{Intracochlear neurosensory cell loss}

To document in detail the histomorphological damage in the inner ear underlying the observed hearing loss, the densities of spiral ganglion neurons and cochlear hair cells were analyzed by immunofluorescence. The analysis was performed for the full length of the cochlea, distinguishing between basal, middle, and apical turns (Fig. $3 A$ ).

TUJ-positive spiral ganglion neurons were quantified in control and infected rats 3 weeks after infection (Fig. $3 A-C$ ). We observed a statistically significant decrease in the density of spiral ganglion neurons after infection with the high inoculum in the basal turn (Fig. 3C; $1558 \pm 205.8 \mathrm{TUJ}^{+}$cells $/ \mathrm{mm}^{2}, p<0.0001$ ) compared to control animals $\left(2649 \pm 237.5 \mathrm{TUJ}^{+}\right.$cells $\left./ \mathrm{mm}^{2}\right)$. Furthermore, infection with the high INO also led to a decreased density of SGNs in the middle $\left(1858 \pm 476.2 \mathrm{TUJ}^{+}\right.$cells $/ \mathrm{mm}^{2}$, $p<0.01)$ and apical turns $\left(2408 \pm 281.5 \mathrm{TUJ}^{+}\right.$cells $/ \mathrm{mm}^{2}, p<$ $0.05)$. Infecting the animals with the low and intermediate INOs did not significantly affect the SGN density compared to control animals, independent of the cochlear region. However, after infection with the intermediate INO, we observed in a fraction $(\approx 60 \%)$ of animals a reduced density of SGNs in the basal turn.

We found a negative correlation between the density of SNGs in the basal turn and the inoculum concentration (Spearman's $r=-0.8, p<0.0001, n=20$ ). Furthermore, we observed a positive correlation between the density of SNGs and the anatomical localization in the cochlea (base, middle, and apical turns) in rats infected with the high INO (Spearman's $r=0.71$, $p<0.001, n=18$ ), showing the highest neuronal cell loss in the basal turn.

To quantitatively assess the survival of mechanosensory hair cells in the organ of Corti after pneumococcal meningitis, we performed immunostainings for the hair cell marker Myosin7a on OC whole-mount preparations. Myosin7a-positive inner and outer hair cells were analyzed separately from base to apex in infected and control rats 3 weeks after infection. We observed a predominant loss of OHCs with a gradient of cell loss from base (lowest survival) to apex (highest survival; Fig. 3D). The quantification revealed a statistically significantly decreased number of OHCs in the basal $(3.5 \pm 6.1$ OHCs per $100 \mu \mathrm{m}, p<0.0001)$ and middle turns $(9.2 \pm 11.6$ OHCs per $100 \mu \mathrm{m}, p<0.01)$ of animals infected with the high inoculum compared to controls (36.6 \pm $1.6 \mathrm{OHCs}$ per $100 \mu \mathrm{m}$; Fig. $3 E$ ). The reduced OHC density in the apical turn (high INO) did not reach statistical significance $(17.6 \pm 19.3$ OHCs per $100 \mu \mathrm{m}, p=0.075)$ due to the high variability. Infecting the animals with the intermediate INO led to reduced OHC counts only in the basal turn $(16.7 \pm 13.4$ OHCs per $100 \mu \mathrm{m}, p<0.05$ ), whereas the low INO did not have a statistically significant effect on OHCs at all. Looking only at the basal turn revealed a negative correlation between the OHC counts and the initial inoculum load (Spearman's $r=-0.8, p<$ $0.0005, n=17)$.

In contrast to the substantial loss of OHCs, IHCs are largely protected from damage in this model of pneumococcal meningitis (Fig. $3 F$ ).

In summary, both the SGNs and especially the OHCs are affected upon pneumococcal meningitis in a dose-dependent fashion, with the highest cell loss occurring in the basal region of the cochlea.

\section{Decreased number of presynaptic ribbons in surviving IHCs}

To analyze the connectivity of surviving IHCs to the remaining SGNs, we immunostained the OC whole mounts for CtBP2, which is a component of presynaptic ribbons (Safieddine et al., 2012).

CtBP2 punctae were quantified in surviving IHCs of the basal, middle, and apical turns (in total, $\approx 105-120$ IHCs per cochlea) of control (Fig. 4A) and infected (B) rats 3 weeks after infection. The ribbon counts were statistically significantly lower in the basal (5.3 \pm 1.1 ribbons per IHC, $p<0.001)$, middle $(6.1 \pm 1.9$ ribbons per IHC, $p<0.01)$, and apical turns $(7.0 \pm 0.5$ ribbons per IHC, $p<0.0001$ ) after infection with the high INO (Fig. 4C) compared to control rats (basal, $17.7 \pm 0.9$; middle, $15.9 \pm 0.6$; apical, 17.1 \pm 0.4 ribbons per IHC), showing lost connectivity to SGNs in the entire frequency spectrum. Infecting the animals with the intermediate or low INO led to a significant reduction of presynaptic ribbons only in the basal turn (intermediate INO, $7.4 \pm 3$ ribbons per IHC, $p<0.05$; low INO, $12.7 \pm 0.5$ ribbons per IHC, $p<0.01)$ compared to controls $(17.7 \pm 0.9$ ribbons per IHC).

We found a negative correlation (Fig. 4D; Spearman's $r=$ $-0.97, p<0.0001$ ) between the number of ribbons per IHC and the inoculum load in the basal turn, matching the dosedependent loss of SGNs (Fig. 3C) and OHCs (Fig. 3E).

\section{Discussion}

The aim of this study was to analyze the relationship between the severity of pneumococcal infection and the degree and characteristics of hearing loss, with special emphasis on the detailed damage occurring on sensory cells of the cochlea. We used for this purpose a well-established animal model of pneumococcal meningitis that was used previously in our laboratory (Grandgirard et al., 2007, 2012; Liechti et al., 2014a,b, 2015a,b).

Infecting the animals with three different bacterial inocula resulted in a dose-dependent bacterial growth kinetic in the CSF during the acute phase ( $18 \mathrm{~h}$ after infection). We were thereby able to use the initial inoculum as a regulator of the disease severity and study its effect on meningitis-induced hearing loss.

The inflammatory response in the CSF induced by S. pneumoniae has been demonstrated previously in patients and experimental models, and a panel of relevant cytokines has been proposed (Täuber and Moser, 1999; Coutinho et al., 2013). Here, we confirm increased levels of selected cytokines, including IL$1 \beta$, IL- 6 , TNF- $\alpha$, IFN- $\gamma$, and IL- 10 , during the acute phase of the disease ( $18 \mathrm{~h}$ after infection) in the experimental model used. The proinflammatory IFN- $\gamma$ and the anti-inflammatory IL-10 cytokines were increased after infection with the high INO, suggesting a dose-depended effect or a time-delayed response. Levels of TNF- $\alpha$, which has been identified in vitro (Wu et al., 2015) and in vivo (Aminpour et al., 2005) as a potent ototoxic cytokine, strongly correlated with the long-term hearing threshold shifts in the present experimental model and may thus be considered as a prognostic factor for meningitis-induced hearing loss in a clinical setting. A similar correlation was observed for the proinflammatory cytokines IL- $1 \beta$ and IL- 6 . Experimental data showed that reducing the amount of TNF- $\alpha$ in the CSF via inhibition of the tumor necrosis factor $\alpha$-converting enzyme (TACE) with doxycycline attenuates hearing loss and reduces the loss of spiral ganglion neurons, underlining the detrimental effect of the overshooting inflammatory response as an important ototoxic factor (Meli et al., 2006). However, the otoprotective effect observed cannot be solely attributed to the TACE-inhibiting effect of doxycycline, due to its broad anti-inflammatory properties, including 
A

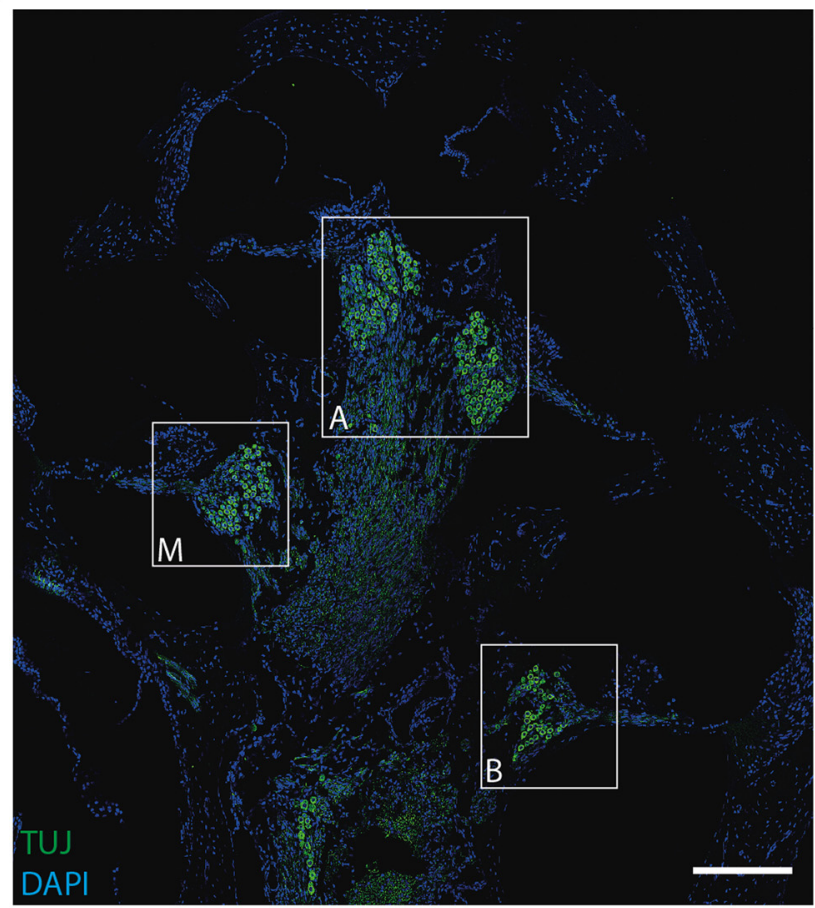

D
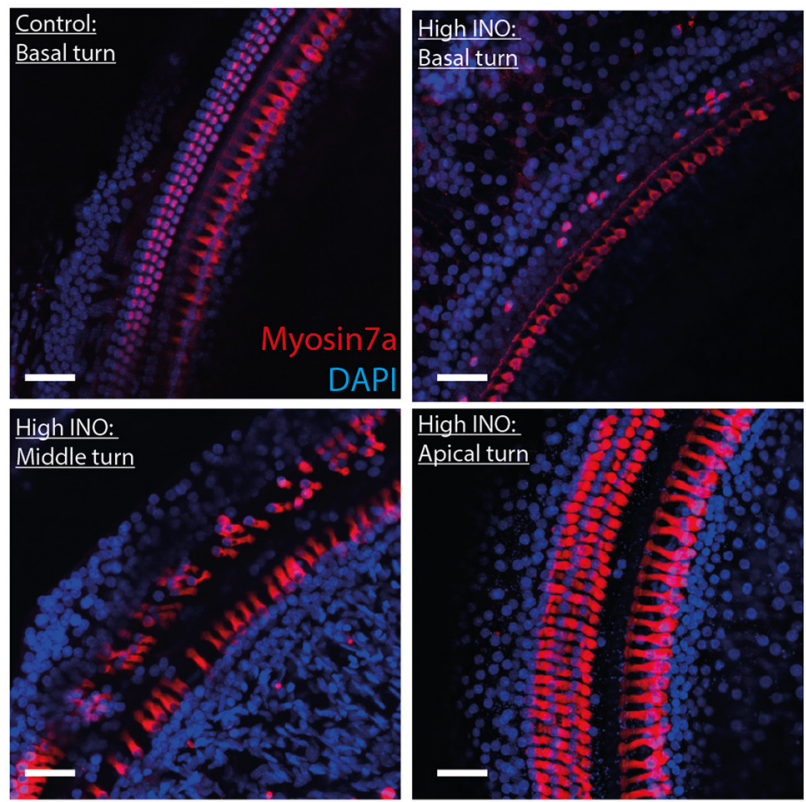

B

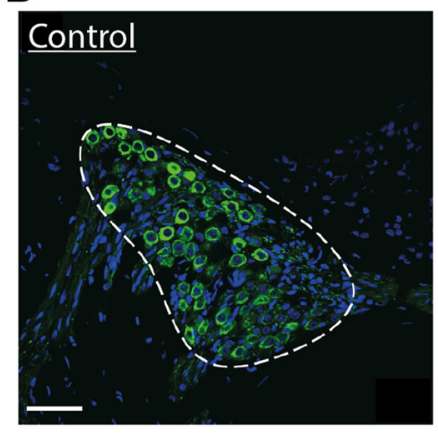

C

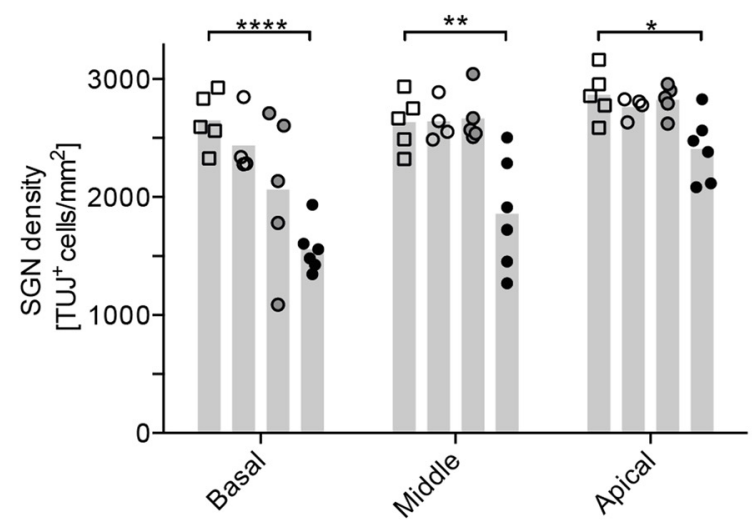

E
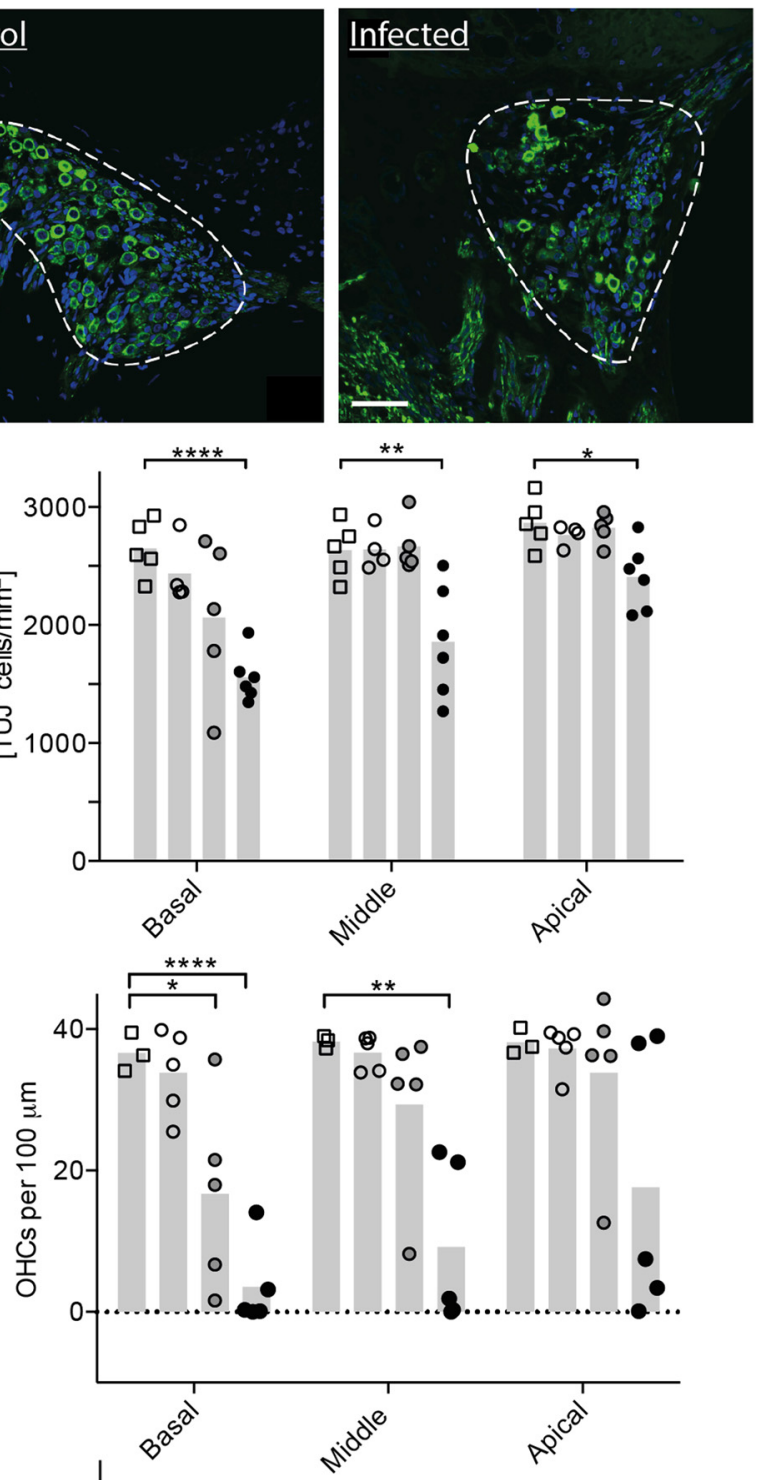

प88 8

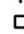

$\mathbf{F}$

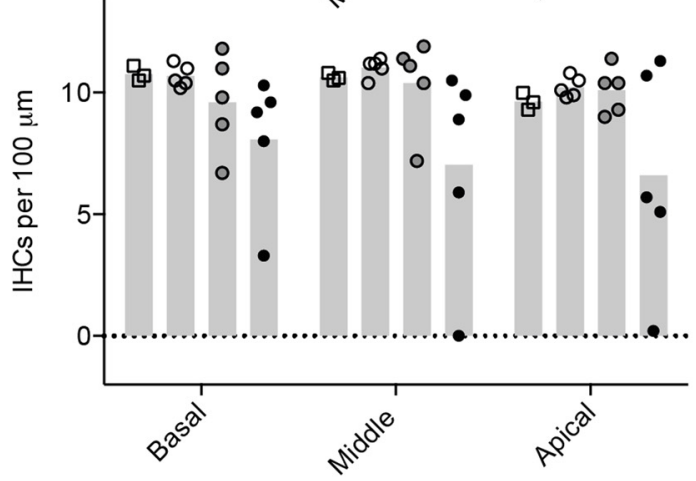

Figure 3. Immunohistological analysis of spiral ganglion neurons and hair cells 3 weeks after infection. $A$, Midmodiolar cross section showing the basal (B), middle (M), and apical (A) turns of a control rat immunostained for neurons (TUJ, green) and cell nuclei (DAPI, blue). $\boldsymbol{B}$, Representative immunostainings of the Rosenthal's canal showing the spiral ganglion (dashed line) in the basal turn of a control animal and an infected animal. C, Neuronal density quantification in the basal, middle, and apical turns in control and infected animals (controls, empty squares; low INO, empty circles; intermediate INO, gray circles; high INO, black circles; $n=4-6$ animals per group). The mean is indicated in the bar graph. An unpaired $t$ test with Welch's correction was used for single comparisons. D, Representative confocal images of the Organ of Corti immunostained for hair cells (Myosin7a, red) and cell nuclei (DAPI, blue). All four pictures were made from the same animal. $\boldsymbol{E}, \boldsymbol{F}$, Quantification of $\mathrm{OHCS}(\boldsymbol{E})$ and $\mathrm{IHCs}(\boldsymbol{F})$ in control and infected animals (controls, empty squares; low INO, empty circles; intermediate INO, gray circles; high INO, black circles; $n=3-5$ animals per group). The means are indicated in the bar graphs. An unpaired $t$ test with Welch's correction was used for single comparisons. Scale bars: $\boldsymbol{A}, 200 \mu \mathrm{m} ; \boldsymbol{B}, \boldsymbol{D}, 50 \mu \mathrm{m} .{ }^{*} p<0.05 ;{ }^{* *} p<0.01 ;{ }^{* * * *} p<0.0001$. 
A

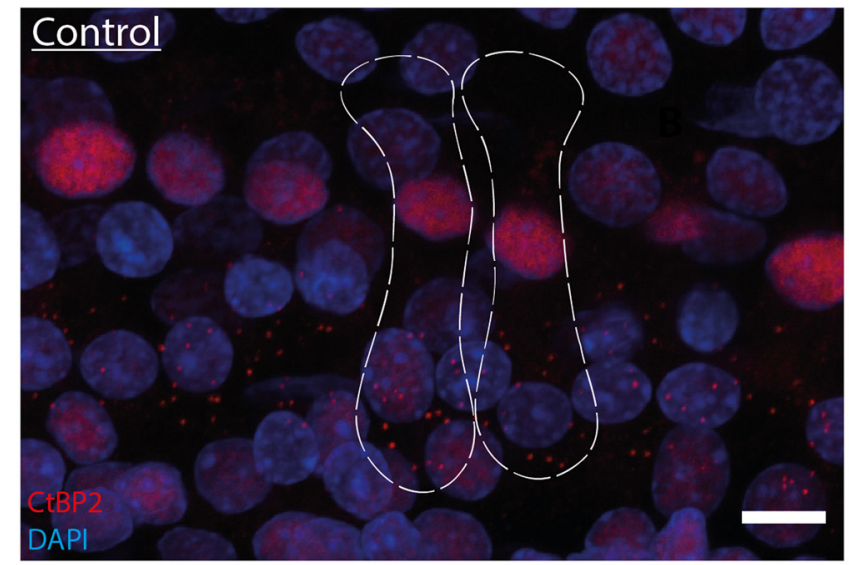

C

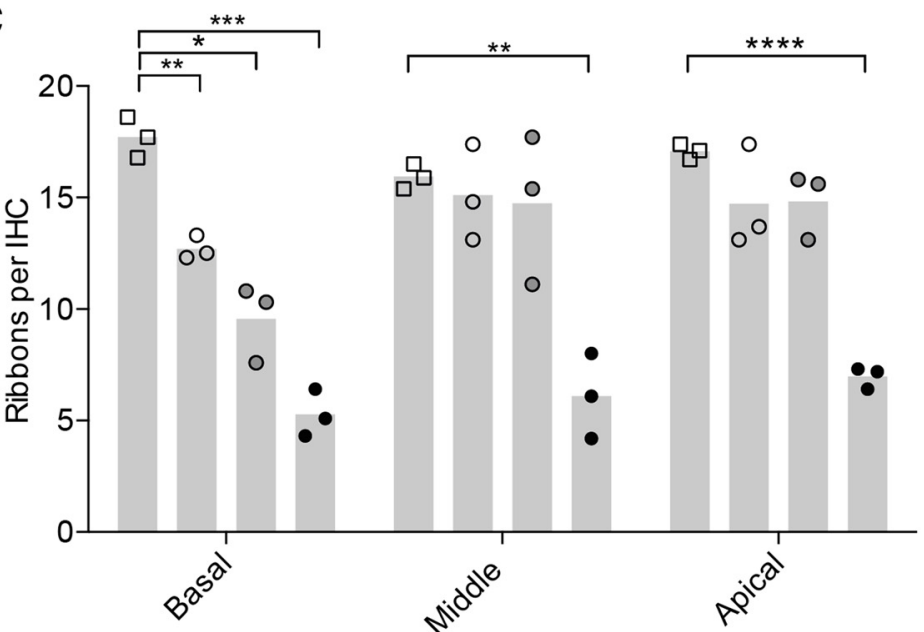

B

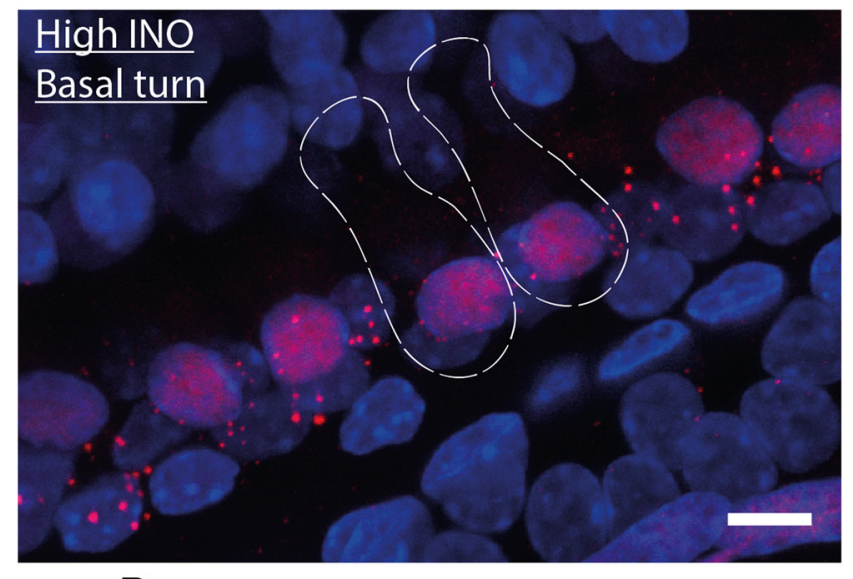

D

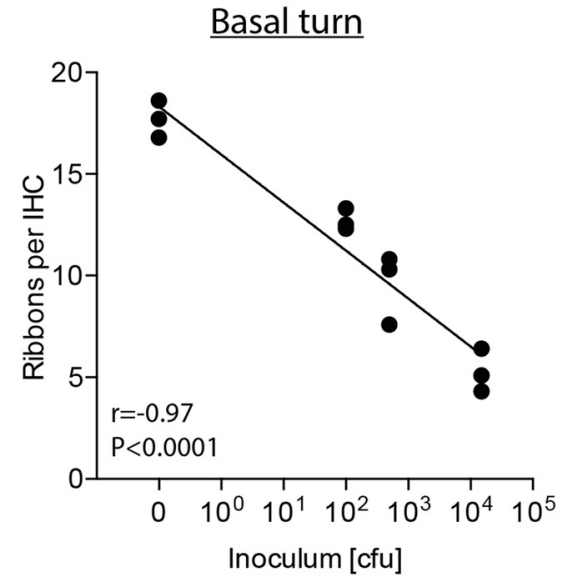

Figure 4. Confocal microscopy analysis of IHC presynaptic ribbons 3 weeks after infection. $A, B$, Representative confocal images (maximal projection from a focal series) of $I H C$ synapses from the basal turn of a control $(\boldsymbol{A})$ and an infected (high IN0; $\boldsymbol{B}$ ) cochlea 3 weeks after infection, immunolabeled for presynaptic ribbons (CtBP2, red) and nuclei (DAPI, blue). The dashed lines show the approximate outlines of two IHCs, determined by immunolabeling for hair cells (Myosin7a, yellow; data not shown). C, Quantification of presynaptic ribbons per IHC for the three cochlear regions in control and infected animals (controls, empty squares; low INO, empty circles; intermediate INO, gray circles; high INO, black circles; $n=3$ per group). The means are indicated in the bar graphs. An unpaired $t$ test with Welch's correction was used for single comparisons. $\boldsymbol{D}$, Spearman's correlation between the number of ribbons per IHC and the initial inoculum load in the basal turn. Scale bars: $10 \mu \mathrm{m} .{ }^{*} p<0.05 ;{ }^{* *} p<0.01 ;{ }^{* * *} p<0.001 ;{ }^{* * *} p<0.0001$.

its effect as an inhibitor of inflammatory matrix metalloproteinases (Roach et al., 2002; Brown et al., 2004). Highly specific and more efficient inhibitors of TNF- $\alpha$ might be promising alternatives, but have not been studied for PM-associated hearing loss. Adjuvant therapy with the nonbacteriolytic antibiotic daptomycin to reduce the inflammatory response has also been shown to attenuate hearing loss in the animal model (Grandgirard et al., 2010, 2012).

Previous studies have identified the concentration of the bacteria used for infection as a determinant of the severity of meningitisinduced brain damage (Giampaolo et al., 1981) and hearing loss (Klein et al., 2003); however, in both cases, this was only assessed $48 \mathrm{~h}$ after infection. Here, we show that the initial bacterial load used for intracisternal infection and therewith the resulting bacterial CSF titer determine the long-term hearing threshold shifts. This finding highlights the importance of a prompt antibiotic therapy to reduce bacterial proliferation and thereby reduce mortality and morbidity, including neurosensory deficits. Indeed, severity of disease, and to a lesser extent, late arrival for treatment, reflected by a history of seizure(s) has been determined as a predictor for profound hearing impairment in a recent cohort of children with bacterial meningitis (Roine et al., 2013). Furthermore, low CSF glucose levels as an indi- cator of the bacterial density and inflammation in CSF has also been shown to be a predictor for hearing loss in childhood meningitis (Woolley et al., 1999).

Cochlear infiltration of pneumococci and leukocytes progresses presumably from the CSF via the cochlear aqueduct into the basal turn of the cochlea (van de Beek et al., 2004; Edmond et al., 2010; Chandran et al., 2011; Møller et al., 2014), resulting in high frequency hearing loss and reduced SNG density in the basal turn (Klein et al., 2003; Meli et al., 2006; Coimbra et al., 2007; Demel et al., 2011; Brand et al., 2014), which is in line with our observations (Fig. $2,3)$. The observed spatial gradient of SGN cell loss (base vs apex), as well as OHC loss documented in this study, supports the hypothesis of the cochlear aqueduct being the primary site of bacterial invasion of the inner ear, resulting in a gradient of ototoxic substances from base (highest concentration) to apex (lowest concentration) and in consequence resulting in a gradient of damage. This hypothesis is also supported by the clinical observation in postmeningitic deaf human patients with ossifications predominantly in the basal turn of the cochlea, sometimes limiting the access for cochlear implantation (Senn et al., 2012).

The route of entrance of toxic inflammatory mediators and/or bacteria into the cochlea during PM still is not clear and is a 
matter of debate. Our study analyzes one possible route of infiltration and consequent cochlear damage, namely, bacterial dissemination from the CSF. The spreading of the bacteria from the bloodstream due to bacteraemia and bacteria traveling along the eighth cranial nerve through the modiolus are two other alternatives discussed in the literature (Klein et al., 2008). Additionally, otitis has been shown to be a main risk factor/predisposing condition for PM-associated hearing loss: toxic inflammatory substances diffuse through the round window membrane, mainly generating cytotoxic damage to the basal region of the cochlea, leading to predominantly high frequency hearing loss (Juhn et al., 1997; Joglekar et al., 2010; Heckenberg et al., 2012).

Our study reveals for the first time a predominant loss of OHCs due to PM. This finding is in line with a previously observed higher vulnerability of OHCs versus IHCs to ototoxic compounds, i.e., aminoglycoside antibiotics, due to differences in mitochondrial metabolism in inner and outer hair cells (Zholudeva et al., 2015). Despite the substantial loss of SGNs and OHCs, the majority of IHCs were still present in the OC even after infecting the animals with the high INO. However, the number of ribbons was reduced. The decrease in the basal turn was dose dependent, with the biggest reduction $(\approx 65 \%)$ after infection with the high INO. Even a mild infection with the low INO had a considerable effect on the ribbon counts, although this was not sufficient to affect hearing thresholds. The severe infection (high INO) dramatically reduced presynaptic ribbons of IHCs across the entire cochlea.

In agreement with the observed damage of SGNs, hair cells, and ribbon synapses predominantly in the basal turn, the biggest hearing threshold shifts were measured at high frequencies (Fig. 2) for the intermediate infections. No frequency dependence was seen in animals that were almost completely deaf after severe infection $(>90 \mathrm{~dB})$, which may be due to the loss of synaptic ribbons across the entire frequency spectrum (Fig. 4).

Together, we have shown that intracisternal infection with $S$. pneumoniae induces a dose-dependent inflammatory response in the CSF. Similarly, subsequent hearing loss, SGN cell loss, OHC cell loss, and loss of IHC ribbon synapses strongly depend on disease severity or the initial bacterial concentration in the CSF. Animals that died during the acute phase of disease due to a severe infection (up to $30 \%$ with high INO) were not analyzed in this study. The main focus was set to determine long-term damages to specific parts of the auditory system in animals that survived the infection, which we think is representative of the clinical picture of surviving patients.

All of these basic cell pathologies, ranging from synaptic damage to functional hearing deficits, offer new possibilities for drugbased interventions. It was shown previously that fibroblast growth factor 22 (FGF22) is able to protect the ribbon synapses from gentamicin ototoxicity (Li et al., 2016). Different drug candidates or a combination of those can be screened for their potency to protect IHC ribbon synapses (like FGF22), outer hair cells, or spiral ganglion neurons in different regions of the cochlea. Furthermore, regeneration of hair cells via activation of somatic progenitor cells (Mizutari et al., 2013) or transplantation of human neural progenitors to repopulate the spiral ganglion might offer regenerative approaches to restore hearing in PM survivors (Chen et al., 2012). Our findings underscore the importance of a swift initiation of antimicrobial therapy and lay the scientific base for an improved management of neurofunctional sequelae including SNHL in patients surviving PM.

\section{References}

Aminpour S, Tinling SP, Brodie HA (2005) Role of tumor necrosis factoralpha in sensorineural hearing loss after bacterial meningitis. Otol Neurotol 26:602-609. CrossRef Medline

Beurg M, Hafidi A, Skinner L, Cowan G, Hondarrague Y, Mitchell TJ, Dulon D (2005) The mechanism of pneumolysin-induced cochlear hair cell death in the rat. J Physiol 568:211-227. CrossRef Medline

Brand Y, Senn P, Kompis M, Dillier N, Allum JH (2014) Cochlear implantation in children and adults in Switzerland. Swiss Med Wkly 144:w13909. Medline

Brandt CT, Cayé-Thomasen P, Lund SP, Worsøe L, Ostergaard C, FrimodtMøller N, Espersen F, Thomsen J, Lundgren JD (2006) Hearing loss and cochlear damage in experimental pneumococcal meningitis, with special reference to the role of neutrophil granulocytes. Neurobiol Dis 23: 300-311. CrossRef Medline

Brown DL, Desai KK, Vakili BA, Nouneh C, Lee HM, Golub LM (2004) Clinical and biochemical results of the metalloproteinase inhibition with subantimicrobial doses of doxycycline to prevent acute coronary syndromes (MIDAS) pilot trial. Arterioscler Thromb Vasc Biol 24:733-738. CrossRef Medline

Chandran A, Herbert H, Misurski D, Santosham M (2011) Long-term sequelae of childhood bacterial meningitis: an underappreciated problem. Pediatr Infect Dis J 30:3-6. CrossRef Medline

Chen W, Jongkamonwiwat N, Abbas L, Eshtan SJ, Johnson SL, Kuhn S, Milo M, Thurlow JK, Andrews PW, Marcotti W, Moore HD, Rivolta MN (2012) Restoration of auditory evoked responses by human ES-cellderived otic progenitors. Nature 490:278-282. CrossRef Medline

Coimbra RS, Loquet G, Leib SL (2007) Limited efficacy of adjuvant therapy with dexamethasone in preventing hearing loss due to experimental pneumococcal meningitis in the infant rat. Pediatr Res 62:291-294. CrossRef Medline

Coutinho LG, Grandgirard D, Leib SL, Agnez-Lima LF (2013) Cerebrospinal-fluid cytokine and chemokine profile in patients with pneumococcal and meningococcal meningitis. BMC Infect Dis 13:326. CrossRef Medline

Demel C, Hoegen T, Giese A, Angele B, Pfister HW, Koedel U, Klein M (2011) Reduced spiral ganglion neuronal loss by adjunctive neurotrophin-3 in experimental pneumococcal meningitis. J Neuroinflammation 8:7. CrossRef Medline

Edmond K, Clark A, Korczak VS, Sanderson C, Griffiths UK, Rudan I (2010) Global and regional risk of disabling sequelae from bacterial meningitis: a systematic review and meta-analysis. Lancet Infect Dis 10:317-328. CrossRef Medline

Ge NN, Brodie SA, Tinling SP, Brodie HA (2004) The effects of superoxide dismutase in gerbils with bacterial meningitis. Otolaryngol Head Neck Surg 131:563-572. CrossRef Medline

Giampaolo C, Scheld M, Boyd J, Savory J, Sande M, Wills M (1981) Leukocyte and bacterial interrelationships in experimental meningitis. Ann Neurol 9:328-333. CrossRef Medline

Grandgirard D, Schürch C, Cottagnoud P, Leib SL (2007) Prevention of brain injury by the nonbacteriolytic antibiotic daptomycin in experimental pneumococcal meningitis. Antimicrob Agents Chemother 51: 2173-2178. CrossRef Medline

Grandgirard D, Oberson K, Bühlmann A, Gäumann R, Leib SL (2010) Attenuation of cerebrospinal fluid inflammation by the nonbacteriolytic antibiotic daptomycin versus that by ceftriaxone in experimental pneumococcal meningitis. Antimicrob Agents Chemother 54:13231326. CrossRef Medline

Grandgirard D, Burri M, Agyeman P, Leib SL (2012) Adjunctive daptomycin attenuates brain damage and hearing loss more efficiently than rifampin in infant rat pneumococcal meningitis. Antimicrob Agents Chemother 56:4289-4295. CrossRef Medline

Haake SM, Dinh CT, Chen S, Eshraghi AA, Van De Water TR (2009) Dexamethasone protects auditory hair cells against TNF $\alpha$-initiated apoptosis via activation of PI3K/Akt and NF $\kappa$ B signaling. Hear Res 255:22-32. CrossRef

Heckenberg SG, Brouwer MC, van der Ende A, Hensen EF, van de Beek D (2012) Hearing loss in adults surviving pneumococcal meningitis is associated with otitis and pneumococcal serotype. Clin Microbiol Infect 18:849-855. CrossRef Medline

Joglekar S, Morita N, Cureoglu S, Schachern PA, Deroee AF, Tsuprun V, Paparella MM, Juhn SK (2010) Cochlear pathology in human temporal 
bones with otitis media. Acta Otolaryngol 130:472-476. CrossRef Medline

Juhn SK, Jung TTK, Lin J, Rhee CK (1997) Effects of Inflammatory Mediators on Middle Ear Pathology and on Inner Ear Function. Ann N Y Acad Sci 830:130-142. CrossRef

Kastenbauer S, Klein M, Koedel U, Pfister HW (2001) Reactive nitrogen species contribute to blood-labyrinth barrier disruption in suppurative labyrinthitis complicating experimental pneumococcal meningitis in the rat. Brain Res 904:208-217. CrossRef Medline

Klein M, Koedel U, Pfister HW, Kastenbauer S (2003) Morphological correlates of acute and permanent hearing loss during experimental pneumococcal meningitis. Brain Pathol 13:123-132. Medline

Klein M, Koedel U, Kastenbauer S, Pfister HW (2008) Nitrogen and oxygen molecules in meningitis-associated labyrinthitis and hearing impairment. Infection 36:2-14. Medline

Leib SL, Leppert D, Clements J, Täuber MG (2000) Matrix metalloproteinases contribute to brain damage in experimental pneumococcal meningitis. Infect Immun 68:615-620. CrossRef Medline

Li S, Hang L, Ma Y (2016) FGF22 protects hearing function from gentamycin ototoxicity by maintaining ribbon synapse number. Hear Res 332: 39-45. CrossRef Medline

Liechti FD, Grandgirard D, Leppert D, Leib SL (2014a) Matrix metalloproteinase inhibition lowers mortality and brain injury in experimental pneumococcal meningitis. Infect Immun 82:1710-1718. CrossRef Medline

Liechti FD, Stüdle N, Theurillat R, Grandgirard D, Thormann W, Leib SL (2014b) The mood-stabilizer lithium prevents hippocampal apoptosis and improves spatial memory in experimental meningitis. PLoS One 9:e113607. CrossRef Medline

Liechti FD, Bächtold F, Grandgirard D, Leppert D, Leib SL (2015a) The matrix metalloproteinase inhibitor RS-130830 attenuates brain injury in experimental pneumococcal meningitis. J Neuroinflammation 12:43. CrossRef Medline

Liechti FD, Grandgirard D, Leib SL (2015b) The antidepressant fluoxetine protects the hippocampus from brain damage in experimental pneumococcal meningitis. Neuroscience 297:89-94. CrossRef Medline

Meli DN, Coimbra RS, Erhart DG, Loquet G, Bellac CL, Tauber MG, Neumann U, Leib SL (2006) Doxycycline reduces mortality and injury to the brain and cochlea in experimental pneumococcal meningitis. Infect Immun 74:3890-3896. CrossRef

Mizutari K, Fujioka M, Hosoya M, Bramhall N, Okano HJ, Okano H, Edge AS (2013) Notch inhibition induces cochlear hair cell regeneration and recovery of hearing after acoustic trauma. Neuron 77:58-69. CrossRef Medline

Møller MN, Brandt C, Østergaard C, Cayé-Thomasen P (2014) Bacterial invasion of the inner ear in association with pneumococcal meningitis. Otol Neurotol 35:e178-86. CrossRef Medline
Rappaport JM, Bhatt SM, Lauretano AM, Kimura RS, Lauretano AM, Levine RA (1999) Electron Microscopic Temporal Bone Histopathology in Experimental Pneumococcal Meningitis. Ann Otol Rhinol Laryngol 108: 537-547. CrossRef Medline

Roach DM, Fitridge RA, Laws PE, Millard SH, Varelias A, Cowled PA (2002) Up-regulation of MMP-2 and MMP-9 leads to degradation of type IV collagen during skeletal muscle reperfusion injury; protection by the MMP inhibitor, doxycycline. Eur J Vasc Endovasc Surg 23:260-269. CrossRef Medline

Roine I, Pelkonen T, Cruzeiro ML, Kataja M, Peltola H, Pitkäranta A (2013) Hearing impairment and its predictors in childhood bacterial meningitis in Angola. Pediatr Infect Dis J 32:563-565. CrossRef Medline

Safieddine S, El-Amraoui A, Petit C (2012) The auditory hair cell ribbon synapse: from assembly to function. Annu Rev Neurosci 35:509-528. CrossRef Medline

Senn P, Rostetter C, Arnold A, Kompis M, Vischer M, Häusler R, Ozdoba C, Mantokoudis G, Caversaccio M (2012) Retrograde cochlear implantation in postmeningitic basal turn ossification. Laryngoscope 122:2043-2050. CrossRef Medline

Täuber M, Moser B (1999) Cytokines and chemokines in meningeal inflammation: biology and clinical implications. Clin Infect Dis 28:1-11. CrossRef Medline

van de Beek D, de Gans J, Spanjaard L, Weisfelt M, Reitsma JB, Vermeulen M (2004) Clinical features and prognostic factors in adults with bacterial meningitis. N Engl J Med 351:1849-1859. CrossRef Medline

Winter AJ, Comis SD, Osborne MP, Tarlow MJ, Stephen J, Andrew PW, Hill J, Mitchell TJ (1997) A role for pneumolysin but not neuraminidase in the hearing loss and cochlear damage induced by experimental pneumococcal meningitis in guinea pigs. Infect Immun 65:4411-4418. Medline

Winter AJ, Marwick S, Osborne M, Comis S, Stephen J, Tarlow M (1996) Ultrastructural damage to the organ of Corti during acute experimental Escherichia coli and pneumococcal meningitis in guinea pigs. Acta Otolaryngol 116:401-407. CrossRef Medline

Wong AC, Ryan AF (2015) Mechanisms of sensorineural cell damage, death and survival in the cochlea. Front Aging Neurosci 7:58. Medline

Woolley AL, Kirk KA, Neumann AM Jr, McWilliams SM, Murray J, Freind D, Wiatrak BJ (1999) Risk factors for hearing loss from meningitis in children: The children's hospital experience. Arch Otolaryngol Head Neck Surg 125:509-514. CrossRef Medline

Wu Q, Wang GP, Xie J, Guo JY, Gong SS (2015) Tumor necrosis factor- $\alpha$ induced ototoxicity in mouse cochlear organotypic culture. PLoS One 10:e0127703. CrossRef

Zholudeva LV, Ward KG, Nichols MG, Smith HJ (2015) Gentamicin differentially alters cellular metabolism of cochlear hair cells as revealed by $\mathrm{NAD}(\mathrm{P}) \mathrm{H}$ fluorescence lifetime imaging. J Biomed Opt 20:051032. CrossRef Medline 